Synthesis and Characterization of Zirconia Supported Silicotungstic Acid for Ethyl

\title{
Levulinate Production
}

Shireen Quereshi ${ }^{a b \dagger}$, Ejaz Ahmad ${ }^{b \dagger}$, Kamal Kishore Pant ${ }^{b}$, Suman Dutta ${ }^{a^{*}}$

a Department of Chemical Engineering, Indian Institute of Technology (ISM), Dhanbad, India

${ }^{b}$ Department of Chemical Engineering, Indian Institute of Technology, Delhi, India

*Corresponding Authors: ss.dutta@hotmail.com,kkpant@chemical.iitd.ac.in

$\dagger$ Equal Contribution Authors 


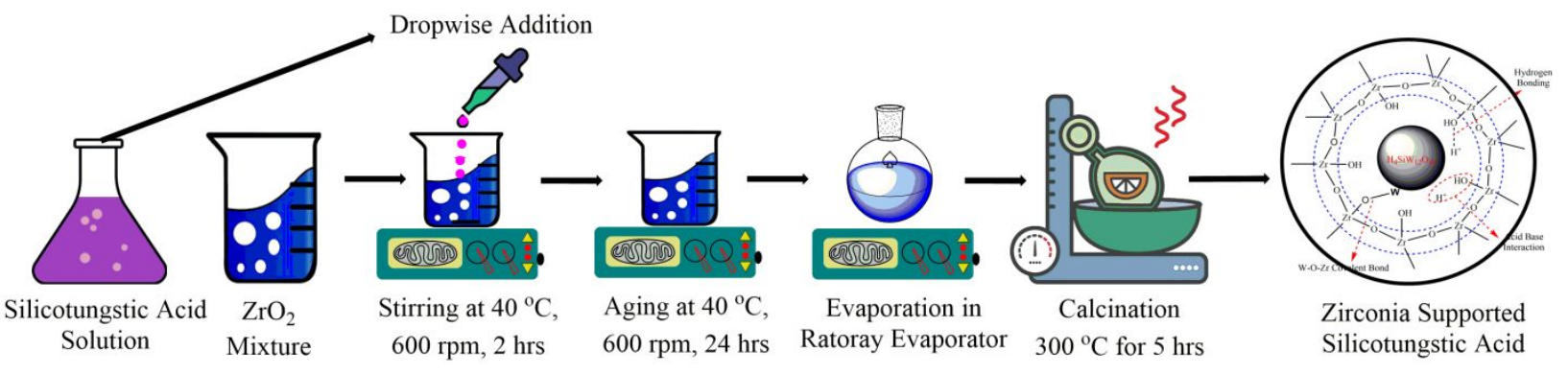

Figure S1 Catalysts Synthesis Procedure Diagram 

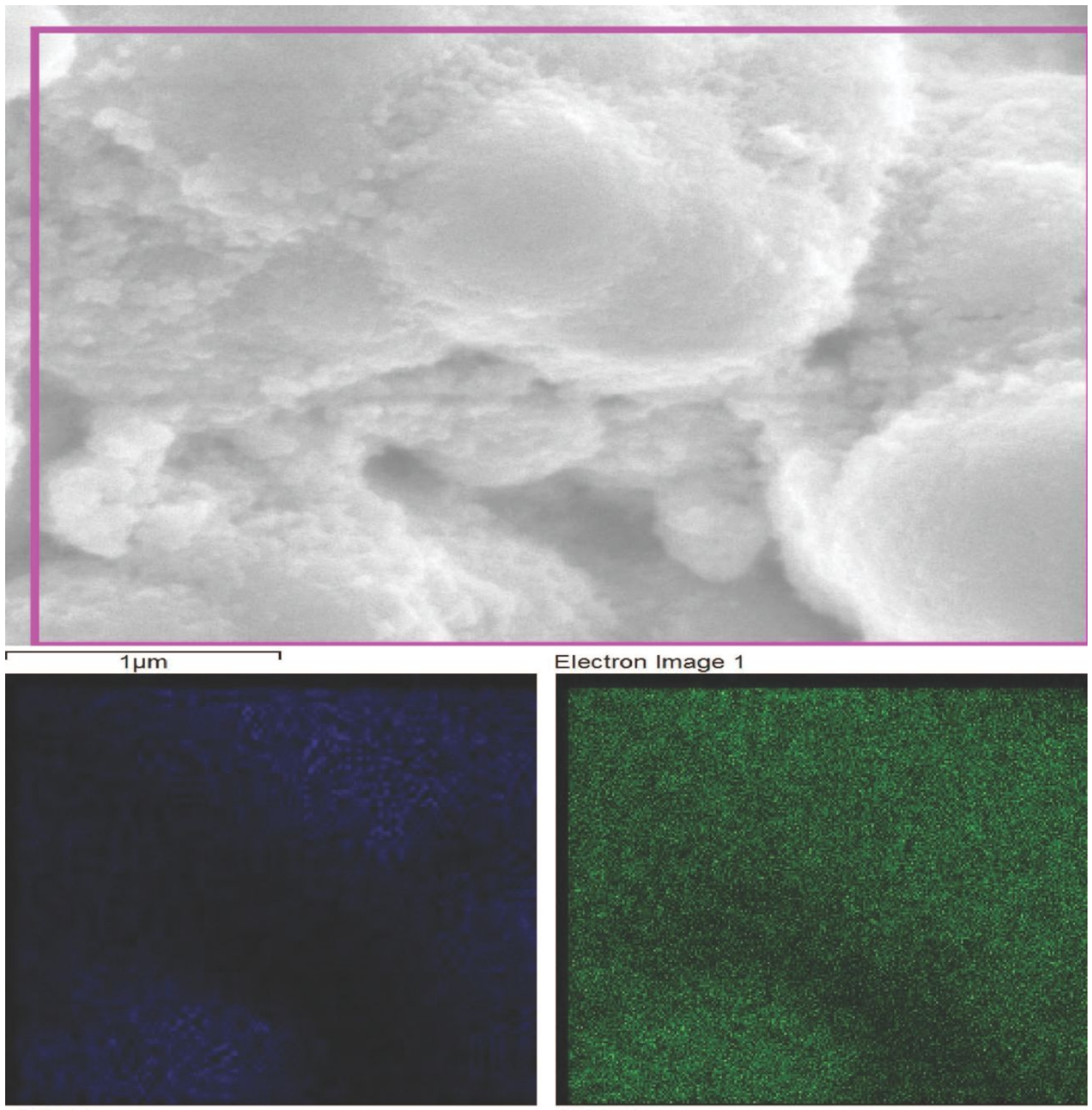

O Ka1

O

Electron Image 1

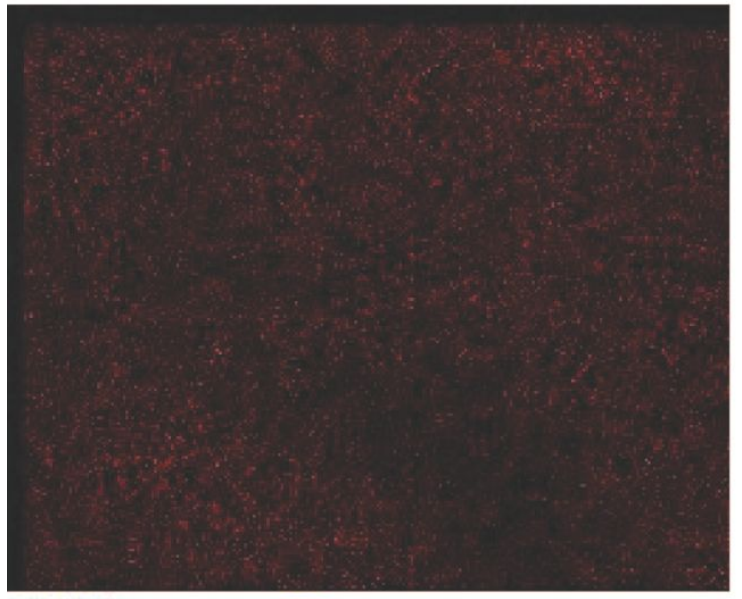

W Ma1

W

Si Ka1

$\mathrm{Zr}$

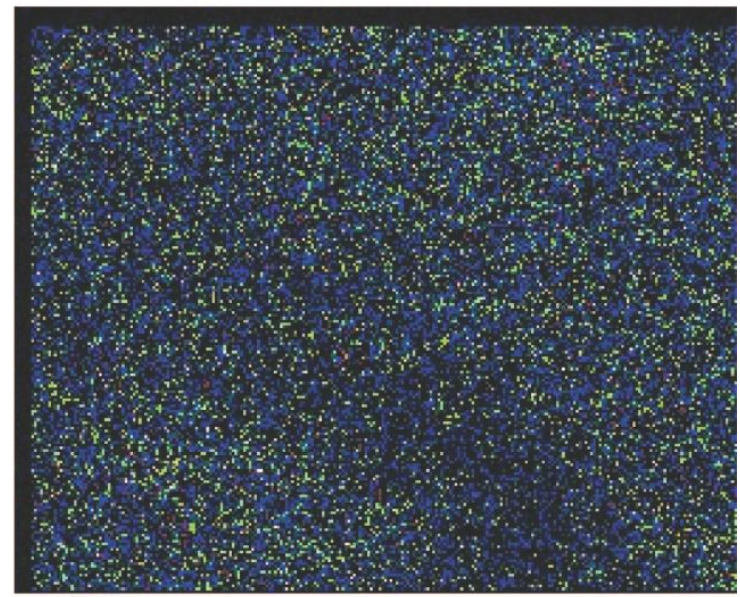


Figure S2 FESEM Mapping Profile of ESZN Catalyst 